\title{
Proposal and Evaluation of Webpage Menu Interface for People with Low Vision
}

\author{
Yujeong Cho ${ }^{1}$, Geunseong Jung ${ }^{2}$ and Jaehyuk $\mathrm{Cha}^{3^{*}}$ \\ Department of Computer Science, Hanyang University, Seoul, Korea \\ ${ }^{1}$ kitty9229@hanyang.ac.kr, ${ }^{2}$ aninteger@hanyang.ac.kr, ${ }^{3}$ chajh@hanyang.ac.kr
}

\begin{abstract}
People with low vision find it difficult to access websites composed of visual contents, which limits them their use of the information provided by such contents. The colorful and inconsistent webpage makes it difficult for them to engage in different activities on the web. To overcome this problem, this study helps design webpage menu interfaces optimized for people with low vision and proposes design rules that can be applied to the existing interfaces. Further, this study proposes vertical and block structure menu interfaces according to the different formats of the hierarchical menu data. To verify the improved usability of the improved menus, the usability evaluation is conducted and compared with the existing websites for evaluation. The evaluation results confirmed that the duration of the task was reduced to half with these two menu interfaces as compared to those with the existing menu interfaces and that the user could understand the hierarchical structure of the websites more quickly and easily while performing the tasks through the block structure menu interface.
\end{abstract}

Keywords: web accessibility, menu interface, people with low vision

\section{Introduction}

Contemporary internet is a major medium for information and services, which enables people to engage in the most basic activities for obtaining information as per their needs. However, the disabled people cannot actively engage in such activities due to their limited access to websites. The current rate of internet use by the disabled people is $70.6 \%$, which is significantly lower than that of people without disabilities with $88.3 \%$. Particularly, the internet use rate by the visually impaired people is $58.1 \%$, which is the lowest in comparison with $75.6 \%$ of the physically disabled people, $63.1 \%$ of the brain lesion disabled people, $62.4 \%$ of the hearing and speech disabled people [1]. These statistics indicate that the need for improving the web environment for the visually impaired people is relatively higher. Approximately $90 \%$ of visually impaired people are people with low vision, who can engage in web activities through residual vision [2]. The reasons that people with low vision have difficulty in web activities and considerations for improving the web environment are described below.

First, numerous websites do not comply with the web accessibility guidelines. Web accessibility refers to the practice of providing equal access to all the content of the websites regardless of disabilities [3]. For the visually impaired people, the excessive use of visual effects on the web, as a constraint on the visual environment, can impair the sight of the visually impaired people further and trigger photosensitive epilepsy in severe cases. Furthermore, the visually impaired people have difficulty

Received (April 16, 2018), Review Result (June 17, 2018), Accepted (June 20, 2018)

* Corresponding Author 
in distinguishing between letters and background when the contrast between the content and background is low.

Second, people with low vision are not well accustomed to the assistive devices that are suitable for them. People with low vision can access the web using their residual vision; however, their vision is so low that they need to use physical assistive devices to view the screen properly. The visual environment for people with low vision disability differs according to the various types of disabilities, such as blurred vision, visual disturbance, and abnormal color vision; thus, the corresponding visual assistive technologies vary as well. However, most of these people know very less about the assistive devices suitable for them, or they cannot afford such assistive devices [4]. For these reasons, a conventional approach has helped the people with low vision to easily use the web by installing SW that provides various functions, such as selecting the screen or adjusting fonts for the people with low vision, even though the use of such SW has been limitedly useful because of the learning requirement for using the SW or compatibility according to the OS environments [4].

Third, the people with low vision are well aware of the structure of a website. The menus provided on the website can help the people with low vision to understand the hierarchical system of the website and find information. However, if the menu of the website is not intuitive and is inconsistent, the menu prevents the people with low vision from understanding the structure of the website and searching it for information [5]. If the menu is redundant or decorated with colorful elements, it disturbs the people with low vision in viewing the menu and places a burden on their eyes [5].

A comprehensive solution to consider and improve all the factors can be obtained that impedes the use of the web by the people with low vision. Web accessibility can be ensured, visual assistive technology can be supported in parallel, and the menu interface can be designed by considering the requirements of the people with low vision. The presentation of the menu in an intuitive and consistent form can help these people easily understand the structure of the website and search for information. Furthermore, it is possible to provide an easy-to-see menu for these people by using the colors that are soothing to the eyes. The improved menu interface can be applied to any website by supporting the menu through the software that is easily installed within the browser.

This study enables us to design two webpage menu interfaces, which are optimized for the people with low vision and proposes design rules that can be applied to the existing interfaces. Further, this study proposes vertical and block structure menu interfaces according to the various methods of representing hierarchical data of menu, and performs usability evaluation to verify the actual usability enhancement effect from the HCI perspective. For usability evaluation, this study performs qualitative usability evaluation using analytical tools as well as quantitative usability evaluation through questionnaire evaluation to compare and evaluate the two interfaces with the existing interface.

\section{Related Work}

\subsection{Web Accessibility}

Web accessibility refers to the comprehensive accessibility of a website to both users with and without disabilities. The disabled users should be allowed to perceive, understand, explore, and interact with the websites equally [3]. The W3C has established the Web Content Accessibility Guidelines (WCAG) 2.0 standard document in order for all websites to meet web-accessibility standards for the 
disabled [3]. In Korea, "KWCAG2.0" suitable for Korea content was established and spread[6].

Table 1. WCAG2.0

\begin{tabular}{|l|l|l|l|l|}
\hline \multirow{5}{*}{ WCAG2.0 } & \multicolumn{1}{|c|}{ 1. Perceivable } & \multicolumn{1}{|c|}{ 2. Operable } & 3. Understandable & \multicolumn{1}{|c|}{ 4. Robust } \\
\cline { 2 - 5 } & 1.1 Text Alternatives & 2.1 KeyboardAccessible & 3.1 Readable & \\
& 1.2 Time-based Media & 2.2 Enough Time & 3.2 Predictable & \multirow{2}{*}{ 4.1 Compatible } \\
& 1.3 Adaptable & 2.3 Seizures & 3.3 Input Assistance & \\
& 1.4 Distinguishable & 2.4 Navigable & & \\
\hline
\end{tabular}

\subsection{Webpage Menu (Web Navigation)}

The websites use a hierarchical navigation structure, with the home page at the top, and different categories below [7].

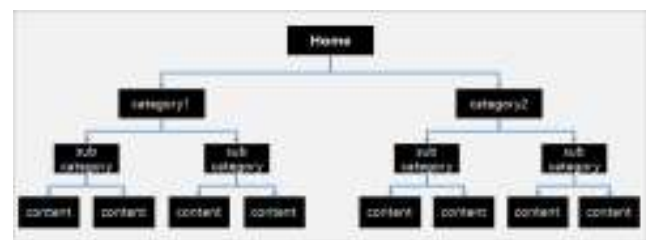

\section{Figure 1. Hierarchical Structure of a Website}

A menu is an interface to assist users in searching for information or conducting programming functions in computer environments. The menus in webpage contexts, which consist of hypertexts or hyper media, support search activities for information [8][9]. In general, a hierarchical information search structure provides two types of web navigation [10]. These are global website navigation that lists core contents on each page and local navigation, a within-text link in a certain page that links to another page [11].

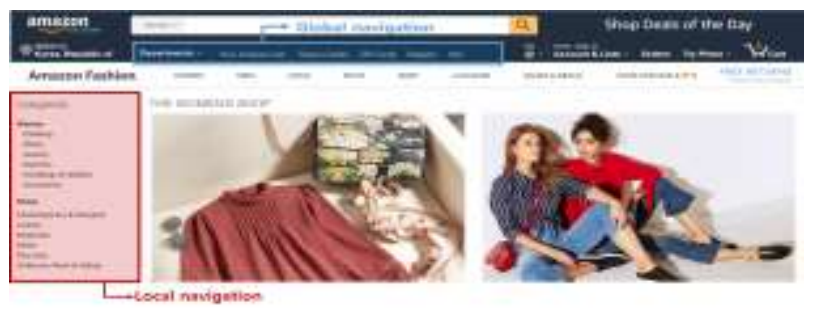

Figure 2. Global and Local Navigation Structures

The global navigation structure represents the top level of a site structure, which displays the entire range of content available to the user with a horizontal navigation bar at the top. The local navigation structure is displayed on the sidebar with a vertical structure, highlighting the current position of the user [10]. Furthermore, there are different types of menus depending on various design methods, such as a text menu that is created by directly hyperlinking texts, an image menu that is designed with images from the design viewpoint, and a flash menu that uses Flash for visual effects [12].

\subsection{Tree Visualization Technique}

The most basic and common techniques for representing the hierarchical data structure are the node-link and space-filling techniques. The node-link technique represents the hierarchical structure in a manner that the parent node is directed to 
the child node [14]. It is easy to understand the menu structure because the relation between the upper and lower menus are intuitively displayed. However, if the hierarchical size becomes large or the hierarchical data is unbalanced, the node-link technique is disadvantageous as visualization consumes a large space. The spacefilling technique complements the disadvantage of the node-link technique, which uses space inefficiently [13].

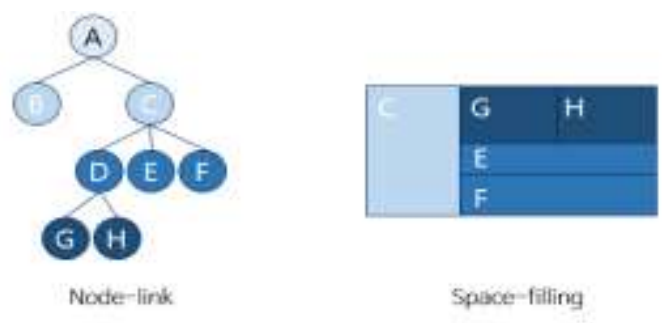

Figure 3. Node-link and Space-Filling Techniques

\subsection{Usability Testing}

Usability refers to the degree of accessibility in using any tool or human-made object or service to achieve a certain purpose [15]. Usability testing measures the convenience of using certain software or products. The testing can be divided into quantitative assessment, where objective data are measured and analyzed, and qualitative assessment. [18]. Qualitative usability evaluation, which assesses user experience and behavior, is difficult to quantify numerically and is focused on collecting subjective opinions of the users [18].

\subsubsection{KLM-GOM}

Efficiency is a critical assessment criterion from a systems engineering perspective [17]. For qualitative evaluation, the GOMS model is typically adopted. The GOMS model is an analytical usability-testing technique to measure the time taken by users to perform given tasks in a certain system. It is hypothesized that the tests will be completed without any mistakes because the human behaviors are defined by goal, operation, method, and selection rules, and therefore, users are aware of the tasks they are meant to perform. Through the GOMS model, design information on the scope and consistency of functions, sequence of operators, execution time of tasks, learning time of procedures, and errors can be obtained objectively[19].

The KLM (or Keystroke-level model)-GOMS is a key-input-based model to predict the total amount of time spent performing tasks such as button or mouse operation [20, 21].

Table 3 lists some of the KLM-GOMS elements, which consist of three physical operators, two mental operators, and one system response operator [17, 22].

Table 2. KLM-GOMS Operator Elements

\begin{tabular}{|c|l|c|}
\hline \multicolumn{2}{|c|}{ Operator/ Description and Remarks } & Time \\
\hline $\mathrm{K}$ & Keystroke or button press & 0.2 \\
\hline $\mathrm{P}$ & pointing to a target on a display with a mouse & 1.1 \\
\hline $\mathrm{H}$ & homing the hand(s) on the keyboard or other device & 0.4 \\
\hline $\mathrm{M}$ & mentally preparing for executing physical actions & 1.35 \\
\hline $\mathrm{R}$ & response time of the system & 0.5 \\
\hline $\mathrm{S}$ & When a new screen appears, check the menu & $\mathrm{t}$ \\
\hline
\end{tabular}




\subsection{People with Low Vision}

According to the statistics, the visually impaired people account for approximately $10 \%$, that is, around 0.25 million of the people with disabilities, and $90 \%$ of the 0.25 million visually impaired people are categorized as those having low vision [2].

Table 3. Statistics by Disability Types

\begin{tabular}{|c|c|c|c|c|c|c|c|}
\hline \multirow{2}{*}{ Total } & \multicolumn{4}{|c|}{ Physical disabilities } & \multicolumn{2}{c|}{ Mental disabilities } & \multirow{2}{*}{ Others } \\
\cline { 2 - 8 } & Developmental & Brain lesion & Visual & Hearing & Intellectual & Mind & \\
\hline $2,511,051$ & $1,267,174$ & 250,456 & 252,794 & 271,843 & 195,283 & 100,069 & 173,432 \\
\hline
\end{tabular}

Although people with low vision experience difficulty in processing visual contents, their residual sight allows them to use the web. Typically, they can be categorized into having decreased visual acuity, visual field defects, or color blindness. The type of blurred vision refers to a condition in which the vision is so low that an individual cannot clearly distinguish an object, it is impossible to correct the vision with a surgery, and the objects are blurred while viewing the screen. Visual disturbance refers to a phenomenon in which a partial loss of vision interferes with viewing the entire screen. Abnormal color vision refers to symptoms in which colors are not distinguished; and red-green color blindness is the most common in this type, which makes it difficult for an individual to distinguish between red and blue. Extreme color blindness refers to a symptom in which colors are not completely distinguished, and objects appear to be in grayscale.

\section{Interface Design Guidelines and Implementation}

\subsection{Analysis of the Requirements of Low Vision Users}

An analysis of user requirements is most important in improving the website menu interface suitable for the people with low vision. The complaints based on the visually impaired users' experiences of the website are provided in Table 5. Note that they are organized according to the evaluation criteria of the visual elements of a menu interface. The majority of the comments indicate that the menus made website navigation confusing because the menus provided by the websites of major organizations are difficult to understand or complex in structure.

Table 4. Complaints about using Websites

\begin{tabular}{|c|c|}
\hline Complaint No. & Details on complaints about using websites \\
\hline $\mathrm{C} 1$ & $\begin{array}{l}\text { Duplicate menus on the web pages are complex and distracting, and the } \\
\text { hierarchy of menus is difficult to understand }\end{array}$ \\
\hline $\mathrm{C} 2$ & $\begin{array}{l}\text { When the user hovers the mouse over the main menu, if the submenu is } \\
\text { displayed in a distance, the hierarchy of menus is difficult to understand }\end{array}$ \\
\hline $\mathrm{C} 3$ & It is difficult to perceive the current location of the mouse cursor \\
\hline $\mathrm{C} 4$ & $\begin{array}{l}\text { The spacing between the upper and lower menus is narrow, and the mouse } \\
\text { control is difficult due to the narrow spacing between menus. Overall, the small } \\
\text { size of the elements for mouse control, such as links and buttons, is inconvenient }\end{array}$ \\
\hline $\mathrm{C} 5$ & $\begin{array}{l}\text { Owing to the small font sizes, it is challenging to recognize menu windows and } \\
\text { contents }\end{array}$ \\
\hline C6 & $\begin{array}{l}\text { It is difficult to distinguish the background colors from the letter colors in the } \\
\text { menu box }\end{array}$ \\
\hline $\mathrm{C} 7$ & $\begin{array}{l}\text { When the menu is difficult to recognize, even though the sitemap is at the top of } \\
\text { the main page, the SITEMAP item is hard to locate due to the small size }\end{array}$ \\
\hline
\end{tabular}


Failure to recognize the menu on a website occurs when the website does not comply with the "perceivable" principle of accessibility provided by the WCAG 2.0. The information and the user interface components cannot be invisible to all the senses, and all the elements that convey information should be presented in a logical and intuitive manner.

\subsection{Visual Element Design Complying with Web Accessibility Guidelines}

Table 6 summarizes each of the above complaints as requirements for designing the menu by item-wise matching the WCAG 2.0 document provided by $\mathrm{W} 3 \mathrm{C}$ with 'Accessibility for People with Low Vision' document.

\section{Table 5. 'WCAG 2.0' Items Related to Complaints and Requirements for Menu Design Accordingly}

\begin{tabular}{|c|c|c|c|}
\hline \multicolumn{2}{|c|}{$\begin{array}{l}\text { User requirements for responding to } \\
\text { complaints }\end{array}$} & Requirements for menu & $\begin{array}{c}\text { Correspo } \\
\text { nding } \\
\text { complai } \\
\text { nts }\end{array}$ \\
\hline \multirow{5}{*}{$\begin{array}{l}\text { WCAG } \\
2.0\end{array}$} & $\begin{array}{l}{[1.3 .2]} \\
\text { Meaningful Sequence }\end{array}$ & $\begin{array}{l}\text { - Determine the number of levels for the menu for } \\
\text { consistent } \\
\text { - Adopt a simple organization for allowing users to easily } \\
\text { distinguish the upper and lower menus, and understand } \\
\text { the hierarchy of the the } \\
\text { - Label clearly the title and classification for allowing the } \\
\text { lower menu to be inferred from the upper menu only. } \\
\text { - Organize logically the sequence of menus according to } \\
\text { the natural flow of recognition. }\end{array}$ & $\begin{array}{l}\mathrm{C} 1 \\
\mathrm{C} 3 \\
\mathrm{C} 4\end{array}$ \\
\hline & $\begin{array}{l}{[1.3 .3]} \\
\text { Sensory Characteristics }\end{array}$ & $\begin{array}{l}\text { - Prevent the menu from being modified in shape } \\
\text { according to the specific event in manipulating a menu } \\
\text { provided for understanding and operating the contents } \\
\text { that constitutes the menu. }\end{array}$ & $\mathrm{C} 1$ \\
\hline & $\begin{array}{l}\text { [1.4.1] } \\
\text { Use of Color }\end{array}$ & $\begin{array}{l}\text { - Ensure delivery of information on element that displays } \\
\text { the menu regardless of color. Add extra distinction } \\
\text { (elements such as an underline) when the link gets the } \\
\text { focus } \\
\text { - Apply mouse events such as underline or bold type to } \\
\text { the menu content for ensuring the distinction according to } \\
\text { mouse movement. }\end{array}$ & $\begin{array}{l}\mathrm{C} 2 \\
\mathrm{C} 3\end{array}$ \\
\hline & $\begin{array}{l}{[1.3 .1]} \\
\text { Info and Relationships }\end{array}$ & $\begin{array}{l}\text { - Use meaningful markups }(<\mathrm{ul}\rangle,\langle\mathrm{li}\rangle \text {, etc.) to group } \\
\text { form elements that are related to one another. }\end{array}$ & $\mathrm{C} 4$ \\
\hline & $\begin{array}{l}{[1.4 .3]} \\
\text { (Minimum) Contrast }\end{array}$ & $\begin{array}{l}\text { - Set at least a contrast of } 3: 1 \text { between elements } \\
\text { constituting the menu and text. } \\
\text { - Set at least a contrast of } 4.5: 1 \text { between content and text } \\
\text { background. }\end{array}$ & $\begin{array}{l}\text { C5 } \\
\text { C6 }\end{array}$ \\
\hline
\end{tabular}

The text and background of the elements constituting the menu for the people with low vision should have at least a contrast of $3: 1$. Items that should be satisfied for the web accessibility of the people with low vision correspond to the 'perceivable' principle provided by WCAG 2.0. The requirements that can respond to the complaints by the user were matched with these items. Most website menu structures are hierarchical navigation structures. A good recognition of the upper and lower structures of the menu can improve web accessibility. The menu provided by the website is reconfigured with two-level hierarchy with a top-level menu and a 
lower level menu to provide consistent types of menu, and the classification and title of the menu are displayed as text for easy recognition. The menus should be arranged in the same sequence as the existing menus provided by the website.

Table 6. 'Accessibility Requirements for People with Low Vision' Items Related to Complaints and Requirements for Menu Design Accordingly

\begin{tabular}{|c|c|c|c|}
\hline \multicolumn{2}{|c|}{$\begin{array}{l}\text { User requirements for responding to } \\
\text { complaints }\end{array}$} & Requirements for menu & $\begin{array}{l}\text { Correspo } \\
\text { nding } \\
\text { complain } \\
\text { ts }\end{array}$ \\
\hline \multirow{4}{*}{$\begin{array}{l}\text { Accessibility } \\
\text { Requirements for } \\
\text { People with Low } \\
\text { Vision }\end{array}$} & $\begin{array}{l}{[3.1]} \\
\text { Brightness } \\
\text { and } \\
\text { Color }\end{array}$ & $\begin{array}{l}\text { Design the menu information that can be } \\
\text { additionally distinguished (through elements such as } \\
\text { an underline) when the link gets the focus regardless } \\
\text { of } \\
\text { Create menus only with text and link. } \\
\text { - Use the appropriate contrast to configure the menu } \\
\text { screen. }\end{array}$ & $\begin{array}{l}\mathrm{C} 2 \\
\mathrm{C} 3\end{array}$ \\
\hline & $\begin{array}{c}{[3.2]} \\
\text { Tracking }\end{array}$ & $\begin{array}{l}\text { - Configure the menu on a single screen without } \\
\text { scrolling to view the menu } \\
\text { - Provides the lower menu underneath the top menu to } \\
\text { support the readability of the site flow and reduce the } \\
\text { navigation errors. } \\
\text { - Add a bold effect to the text menu to intuitively } \\
\text { indicate the page the user is currently reading. }\end{array}$ & $\begin{array}{l}\mathrm{C} 1 \\
\mathrm{C} 2\end{array}$ \\
\hline & $\begin{array}{c}{[3.3]} \\
\text { Perceiving }\end{array}$ & $\begin{array}{l}\text { - Set the text that represents the menu as large and use } \\
\text { fonts that are easy readable for all users. } \\
\text { - Set high contrast between the text and the } \\
\text { background and display them in bold typed to clarify } \\
\text { the size contrast. }\end{array}$ & $\begin{array}{l}\text { C4 } \\
\text { C5 } \\
\text { C6 }\end{array}$ \\
\hline & $\begin{array}{l}{[3.4]} \\
\text { Spacing for } \\
\text { Reading }\end{array}$ & $\begin{array}{l}\text { - Maintain the elements constituting the menu as } \\
\text { evenly spaced for readability. } \\
\text { (Set appropriately the spacing between menus, the } \\
\text { spacing between words, the line spacing, the } \\
\text { character, justification, the margin and the border, and } \\
\text { the spacing between the elements according to the } \\
\text { resolution.) }\end{array}$ & $\begin{array}{l}\text { C4 } \\
\text { C5 } \\
\text { C6 }\end{array}$ \\
\hline
\end{tabular}

To improve visual elements overall, the requirements summarized in the above table were addressed and the document, "Accessibility Requirements for People with Low Vision," provided by $\mathrm{W} 3 \mathrm{C}$ was referred to when designing the interface[23].

\subsection{Interface Design for Web Accessibility of People with Low Vision}

To provide an efficient navigation experience, an optimized menu interface for visually impaired users was designed. First, the menu hierarchical structure is visualized in two steps using the node-link and the space-filling techniques. Each element of the two-level menu interface, visualized through each technique, is designed in compliance with the web accessibility guidelines to incorporate the requirements of people with low vision. The design rules and design steps for the two proposed interfaces, which can be applied to the existing interfaces, are described below. The overall designs of the two interfaces for each technique are shown in Figures 4 and 5. 


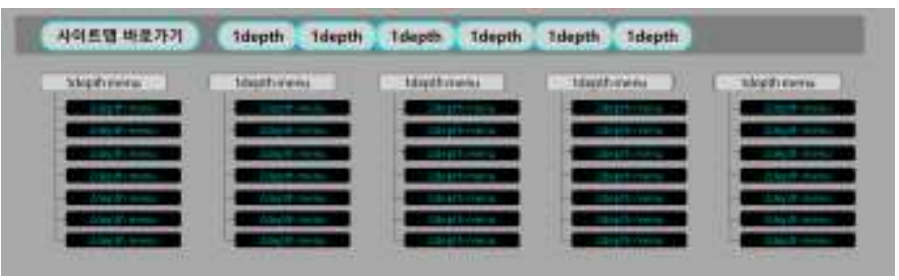

Figure 4. Vertical Structure Menu Interface

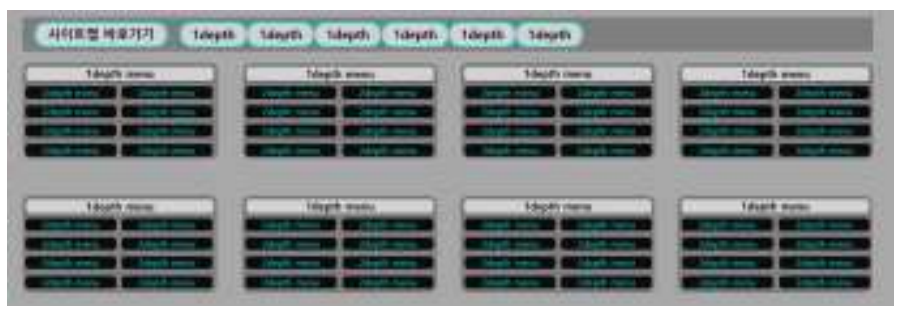

Figure 5. Block Structure Menu Interface

The vertical structure menu interface intuitively represents the hierarchical structure. The lower menus underneath the upper menu are vertically arranged in a line, and the relationship between the upper and lower menus can be grasped easily. The sequence of the menu is the same as that of the menu on the website. The block structure menu interface does not depend on the size of the menu data, displaying the menu in a certain form on the screen. The lower menus are arranged in two lines below the upper menu, filling the space of the screen. Both interfaces are created only with text menu hyperlinking texts. The design rules applied to the above two interfaces are described ahead.

[Design Rule 1]. The colors applied to the interface are limited to the following five colors.

Table 7. Five Color Codes used in the Menu Interface

\begin{tabular}{|c|c|c|c|c|}
\hline & & & & \\
\hline \#7C7C7C & \#DEDEDE & \#000000 & \#56B4E9 & \#F0E442 \\
\hline
\end{tabular}

As bright colors might burden the eyes and evoke eye pains for the visually impaired users, only five colors are chosen to maintain a consistent style. The color code is determined only after identifying the colors that people with color blindness can distinguish from the others [24]. The grayscale \# 7C7C7C color code is used for the background color of the menu interface to reduce the glare and to set the overall background brightness to low brightness because bright light can place a burden on the eyes of people with low vision. The colors applied to each component are explained in the course of designing each component.

[Design Rule 2]. The hierarchical structure of the global navigation structure on the website is divided to configure the menu into a single hierarchical menu with two depths. 


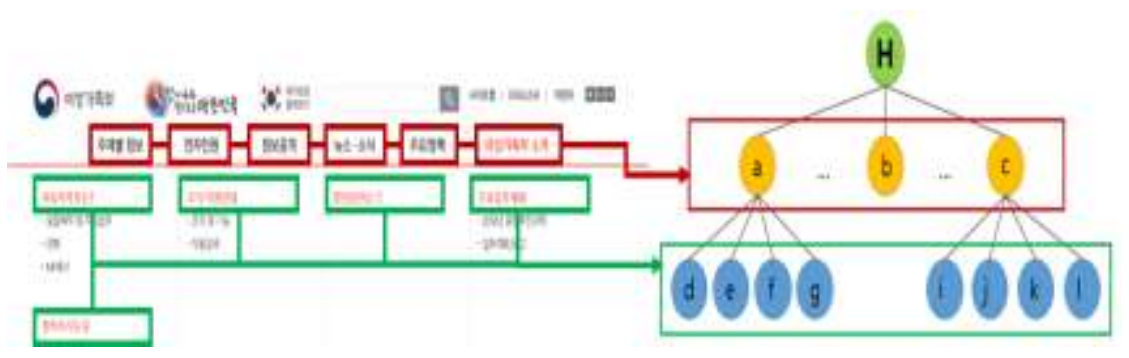

Figure 6. Hierarchical Structure of a Menu on the Website (sample site source: Ministry of Gender Equality and Family of Korea)

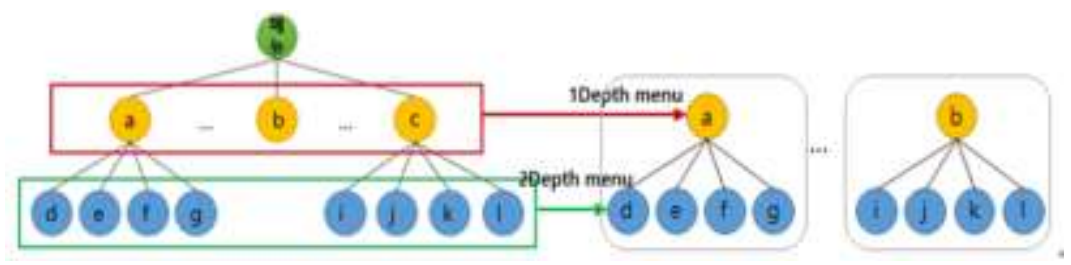

Figure 7. Separation into a Single Menu with Two Depths

The hierarchy of menu is separated to reconfigure the menu into a single menu with two depths, which results in a certain hierarchical structure consisting of the menu corresponding to the top-level category and the submenu. The color is set by representing the reconfigured single menu with vertical and block structures.
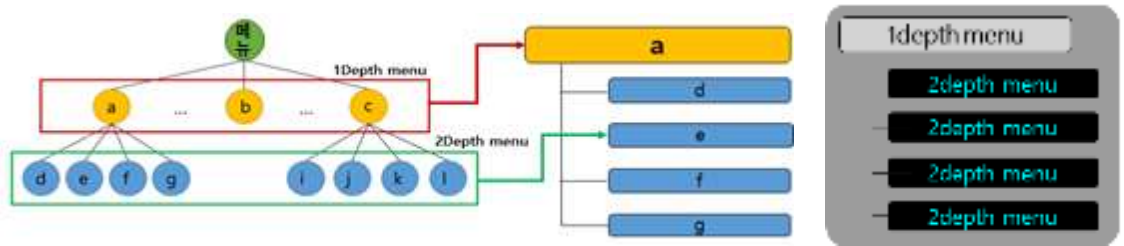

Figure 8. Menu Representation (left) and Color Setting (right) of the Vertical Structure
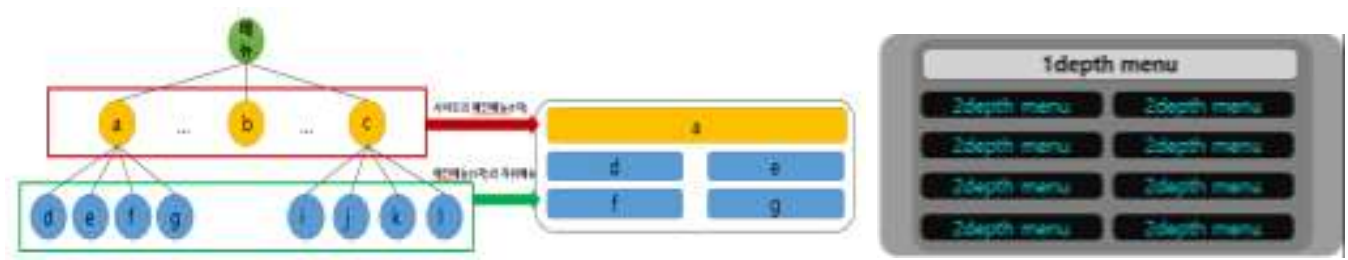

Figure 9. Menu Representation (left) and Color Setting (right) of the Block Structure

The vertical structure has the top-level menu at the top of the node, and the subcategory menus are arranged vertically. The block structure has all the menus in one rectangular block. Above the block structure, the subcategory menus are arranged in a sequence in two lines underneath the top block to fill the square block. Single menus are arranged in the same sequence as the menu on the site for allowing the users to read information in a natural flow, to minimize eye nerve reaction and eye movement time of the people with low vision, thereby reducing eye fatigue. Moreover, single menus reduce the learning time to understand the structure of the menu because the menu is represented in a certain form.

The colors are applied to menus represented in the vertical and block structures according to [conversation rule 1]. The background color for the primary menu 
containing the top category information is set as light gray (\#DEDEDE), and the color for the text that displays the menu is set as black (\# 000000). The light gray color makes the menu area look relatively wide. Black is the most basic color with high contrast as a background color, clearly displaying the text. The colors of the secondary menu can distinguish this menu as a different hierarchical data by setting the background color as black (\# 000000) and the text as light blue (\#56B4E9). A rectangular block with a block structure that surrounds the entire menu is set as gray (\# 7C7C7C) to distinguish the background and the menu.

[Design Rule 3]. 'Site map shortcut' button and the primary menu are listed at the upper left corner of the menu area

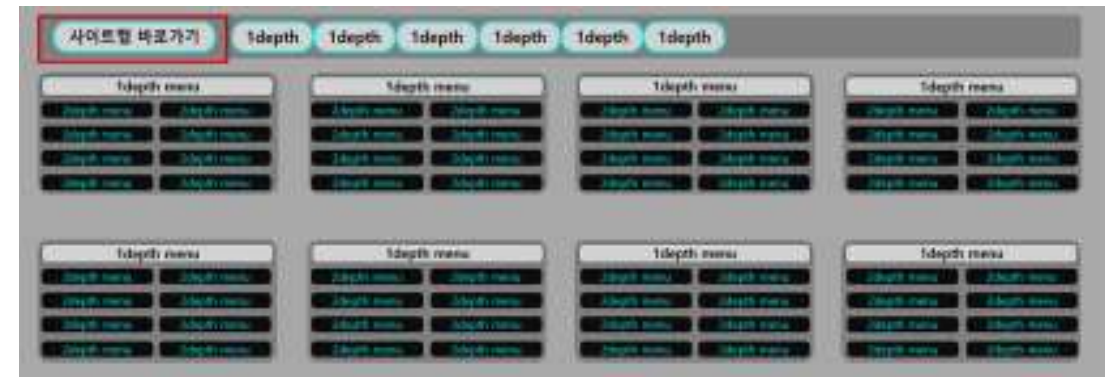

\section{Figure 10. Locations of 'sitemap shortcut' Button and Primary Menu in the Menu Interface}

\section{사이트맵바로가기}

Figure 11. 'Site map shortcut' Button

When exploring a webpage, some visually impaired users prefer to use the "sitemap" of a menu [5]. The sitemap can be used by users who do not recognize the menu of the website because the sitemap shows the entire hierarchy of the website at a glance. A sitemap can be categorized as another type of menu with a different style [25]. Typically, sitemaps are located on the side or hidden and written in small fonts. To address this, one can add a "Go to the sitemap" shortcut button on the upper part of the menu. Next to the 'sitemap shortcut' button, the primary menus are listed horizontally in a row serve as the major page shortcut. Thus, the service provided by the website can be quickly identified. Furthermore, if the submenu (secondary menu) of the primary menu is separated depending on the site, the hierarchical structure is not well revealed. Thus, the menu interface is not configured in a certain form. To prevent this, the first menu is arranged at the upper part to maintain the upper area in a certain form.

The colors for the 'sitemap shortcut' and the primary menu interface element displayed in the upper area are set according to [Design Rule 1]. The background color is set as \#DEDEDE and its text color is set as \# 000000, which are the same colors as the vertical and primary menus of the block structure. The elements become distinct by marking the border of each element with a bold border white light blue (\# 56B4E9). The area looks relatively wide and is easy to notice.

[Design Rule 4]. With a mouseover event, the changes related to the backgrounds, texts, colors, and thicknesses of border lines are applied to all menu buttons. 

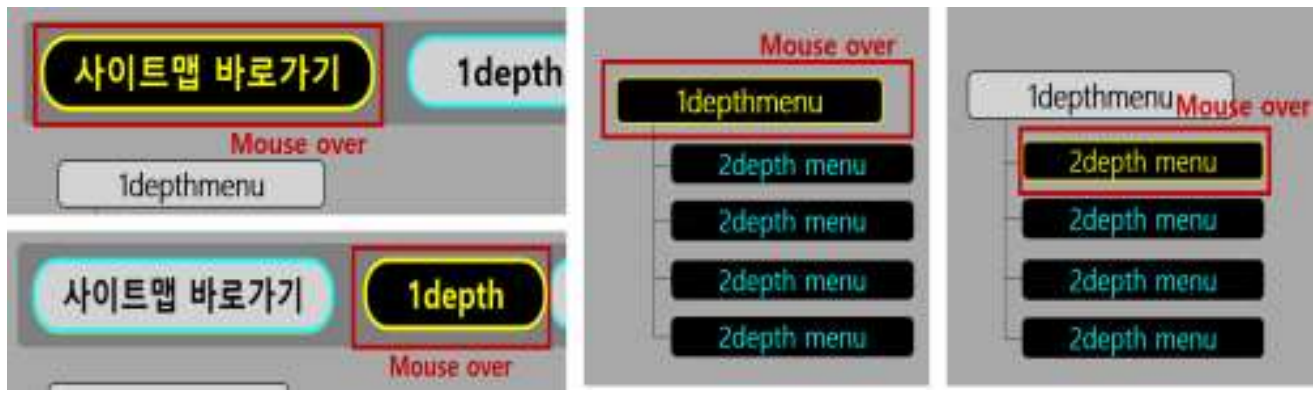

\section{Figure 12. Application of Mouseover Event on Vertical Structure Menu} Interface
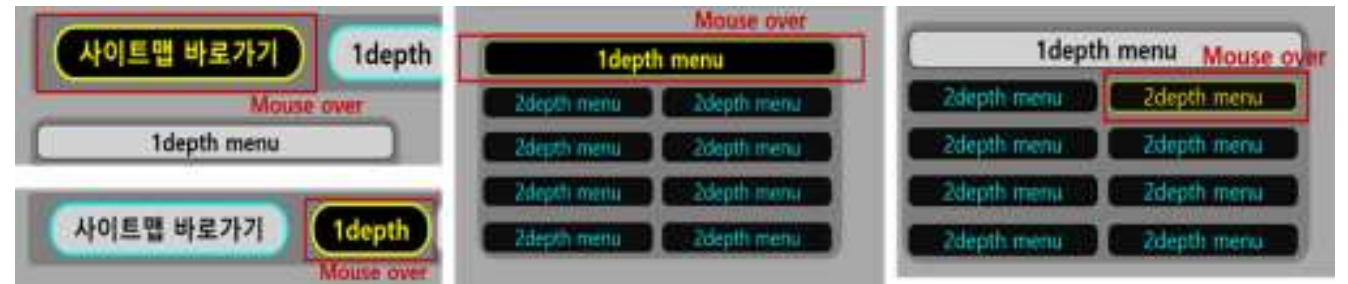

Figure 13. Application of Mouseover Event on Block Structure Menu
Interface

To abide by the guideline to make contents perceivable despite colors, changes should be perceived by changing the background color, text color, and thickness of borderlines in all menu-block elements in the case of a mouseover event. Visual events that can cause photosensitive epilepsy are excluded, which makes it possible to detect the position of the current cursor by the changes in the background, text color, and border thickness, which also allow the detection of the current position of the cursor. Additionally, most users with color blindness cannot perceive the color changes between red and blue; thus, yellow (\#F0E442) and blue (56B4E9) were chosen for the color change during a mouseover event [26]. The mouseover events are all handled in the same mannered as discussed previously. When the cursor moves up, the background color of the element changes to black (\# 000000), and the colors of the text and border change to yellow (\# F0E442). The bold effect is applied to the text, intuitively revealing the position where the user is currently reading. When a borderline with high contrast to the background is added, recognizing the shape and colors of a moving target becomes much easier [26]. During the mouseover event, the border becomes twice as thick while the border colors change.

\subsection{Application of Interface for Web Accessibility of People with Low Vision}

In this study, two interfaces were designed according to four design rules. The interface designed to compare the menu shapes represented by the number of menus was applied to the websites. One site with a small menu data and the other site with a large menu were selected. The experimental sites are the 'Welfare Disability Employment Portal' and 'the Ministry of Health and Welfare,' which is the central administrative agency $[27,28]$. The experiments were performed on a 22 -inch LCD display with a resolution of $1920 \times 1080$. 


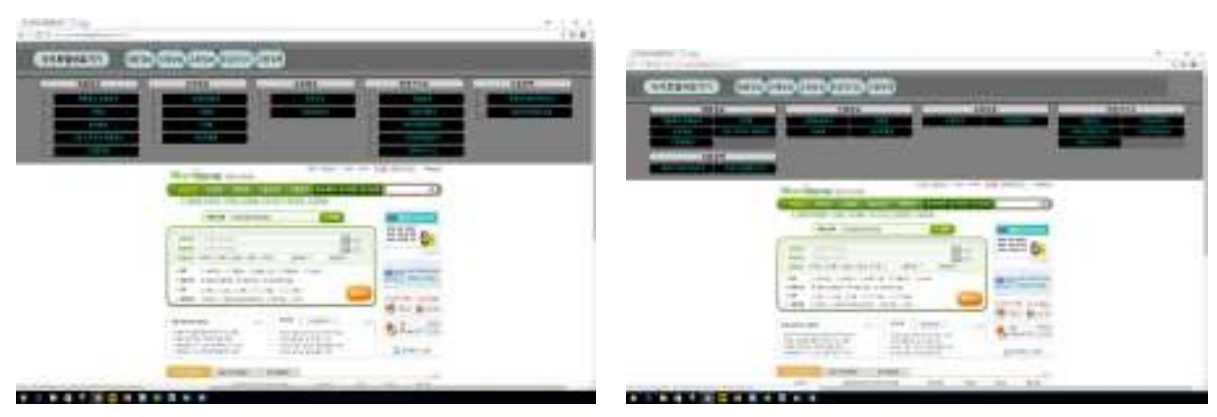

Figure 14. Application of Vertical Structure Menu Interface and Block Structure Menu Interface 1 (example site: Welfare Disability Employment Portal, left: vertical structure, right: block structure)

The 'Welfare Disability Employment Portal,' which is the site for the welfarerelated site for the disabled people, has five or less menu items; thus, containing few menu data. The application results of the vertical and the block structure menu interfaces to this site indicates that the vertical structure menu interface was more balanced due to the small size of the menu data.
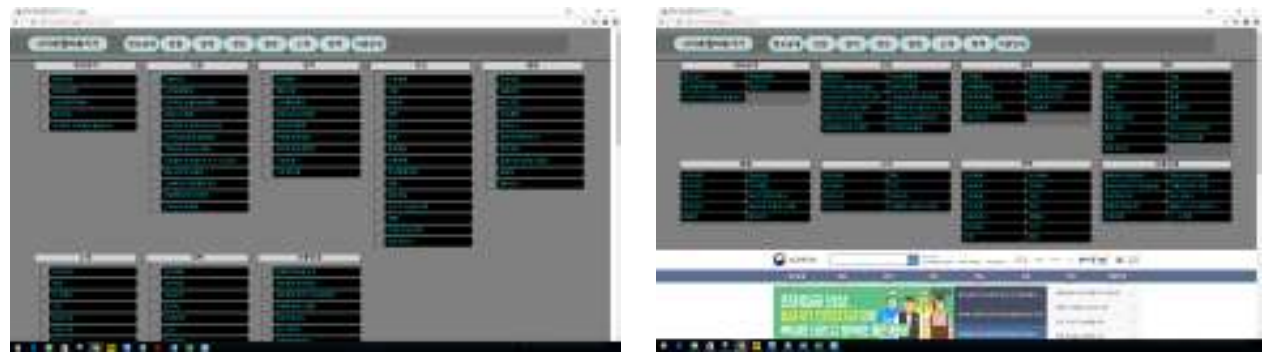

Figure 15. Application of Vertical Structure Menu Interface and Block Structure Menu Interface 2 (example site: Ministry of Health and Welfare, left: vertical structure, right: block structure)

The 'Ministry of Health and Welfare,' which is the website of the central administrative agency, has eight primary menus, and numerous secondary menus. When the vertical structure menu interface is applied, the secondary menus are vertically arranged, occupying a large area to the bottom, to cover the entire area of the existing site. Scrolling is required to navigate through the menus and view the existing site. Contrarily, the block structure menu interface could represent the menus in a balanced form despite the large amount of menu data of 'Ministry of Health and Welfare.' In the block structure, the secondary menus are arranged in two lines below the primary menu; thus, the secondary menus occupy approximately half the space corresponding to the height of the menu displayed in the vertical structure menu interface.

\section{Interface Evaluation}

This study proposed two menu interfaces for people with low vision. These two interfaces are provided for improving the web accessibility. When the visual elements and the hierarchy of the displayed menu are the same, it is necessary to verify if the accessibility and usability of the interface can be improved according to the representation structure of the menu. This study mainly performs three types of evaluations. First, this study evaluates whether the proposed interfaces comply with the web accessibility guidelines. Furthermore, this study performs quantitative and qualitative usability evaluations on these interfaces. Typically, the evaluation is 
performed by using the GOMS model, which is an analytical evaluation tool widely used for quantitative usability evaluation. The performance times of site navigation through the menus are analytically measured to compare the two interfaces with the existing website menu interface. Finally, this study conducts an end-user evaluation to compare and evaluate the three interfaces by collecting objective assessments and subjective opinions, analyzing the user behavior in performing a given task.

\subsection{Evaluation of Web Accessibility Elements using Web Accessibility Tools}

The larger the size of the letter, the higher the contrast between the screen background and the content, the more clearly the people with low vision can distinguish between objects. According to WCAG 2.0 1.4.3 [(Minimum) Contrast], the visual presentation of the background and content $t$ should have a contrast ratio of at least 4.5:1, [3]. In the WCAG criterion, a regular-sized text complies with a contrast ratio of $4.5: 1$ and a large-sized text complies with a contrast ratio of $3: 1$, which are rated as Level AA. Moreover, a regular-sized text complies with a contrast ratio of at least 7:1 and a large-sized text complies with a contrast ratio of 4.5:1, which are rated as Level AAA [29]. A large-sized text means a text with the bold effect and 14 points (18.66 px) or with 18 points (24 px) or larger. A 'color contrast checker' was used to check the contrast ratio of the designed menu interfaces [30].

Table 8. Contrast Ratio Check for Menu Interface Elements

\begin{tabular}{|c|c|c|c|}
\hline Evaluation element & Used colors & Contrast ratio & Rating \\
\hline 사이트맵바로가기 & \multirow{2}{*}{$\begin{array}{l}\text { background color: } \\
\text { \#DEDEDE } \\
\text { foreground color: } \\
\# 000000\end{array}$} & \multirow{2}{*}{$15.61: 1$} & AAA \\
\hline 1depth menu & & & AAA \\
\hline 2depth menu & $\begin{array}{l}\text { background color: } \\
\# 000000 \\
\text { foreground } \\
\# 56 \mathrm{~B} 4 \mathrm{E} 9\end{array}$ & $9.10: 1$ & AAA \\
\hline 사이트맵바로가기 & $\begin{array}{ll}\text { background } & \text { color: } \\
\# 000000 & \\
\text { foreground } & \text { color: } \\
\# \text { F0E442 } & \end{array}$ & 15.88:1 & AAA \\
\hline
\end{tabular}

The interfaces designed in this study complies with Level AAA for all the elements constituting the menus in relation to color combinations applied to background and text of each button; background and border; and mouseover events.

\subsection{Accessibility Checklist for Improved Menu Interface}

This study evaluates whether the improved menu interfaces complied with web accessibility guidelines and the interfaces were designed to incorporate web accessibility requirements for people with low vision. The items to be met to improve the web accessibility for people with low vision correspond to the items in the 'perceivable' principle of accessibility provided by WCAG 2.0 [3]. As shown in Table 10, the evaluation results satisfy the six items in the 'perceivable' principle of accessibility. To incorporate visual elements into the design, this study referred to the 'Accessibility Requirements for People with Low Vision' document provided by W3C [23]. Table 11 shows that 11 items are incorporated in the visual improvement to improve the web accessibility for people with low vision. 
Table 9. 'WCAG 2.0' Checklist

\begin{tabular}{|c|l|c|}
\hline Item & \multicolumn{1}{|c|}{ Checklist } & Compliance \\
\hline 1.3 .1 & $\begin{array}{l}\text { Are the related elements treated as a group? } \\
\text { Are neighboring contents distinguishable? }\end{array}$ & $\mathrm{O}$ \\
\hline $\begin{array}{l}1.3 .2 \\
1.3 .3\end{array}$ & $\begin{array}{l}\text { Are the sequence of the interface elements logically presented to } \\
\text { prevent further learning by the user? }\end{array}$ & $\mathrm{O}$ \\
\hline 1.4 .1 & $\begin{array}{l}\text { For those who cannot distinguish particular colors, is the content } \\
\text { presented for allowing the content to be recognized regardless of } \\
\text { the colors? }\end{array}$ & $\mathrm{O}$ \\
\hline 1.4 .3 & $\begin{array}{l}\text { Is the contrast between the text content and the background set as } \\
\text { at least } 4.5: 1 ?\end{array}$ & $\mathrm{O}$ \\
\hline 1.4 .4 & \begin{tabular}{l} 
Is the text size of the page doubled to make it easier to read? \\
\hline
\end{tabular}
\end{tabular}

Table 10. 'Accessibility Requirements for People with Low Vision' Checklist

\begin{tabular}{|c|c|c|}
\hline Item & Checklist & Compliance \\
\hline $\begin{array}{l}3.1 .1 \\
\text { Brightness Overall }\end{array}$ & $\begin{array}{l}\text { Is the screen brightness dimmed or its brightness } \\
\text { decreased to reduce eye fatigue? }\end{array}$ & $\mathrm{O}$ \\
\hline $\begin{array}{l}3.1 .2 \\
\text { Text Contrast }\end{array}$ & $\begin{array}{l}\text { Is the contrast ratio between the text and the } \\
\text { background at least } 4.5: 1 \text { ? }\end{array}$ & $\mathrm{O}$ \\
\hline $\begin{array}{l}3.1 .3 \\
\text { Not Relying on Color }\end{array}$ & $\begin{array}{l}\text { Is the appropriate style was set to control the weight } \\
\text { of the fonts? }\end{array}$ & $\mathrm{O}$ \\
\hline $\begin{array}{l}3.3 .1 \\
\text { Text Size }\end{array}$ & Is the text size set appropriately? & $\mathrm{O}$ \\
\hline $\begin{array}{l}3.3 .2 \\
\text { Font }\end{array}$ & Are the fonts used that are easy to read by anyone? & $\mathrm{O}$ \\
\hline $\begin{array}{l}3.3 .3 \\
\text { Style }\end{array}$ & $\begin{array}{l}\text { Is the appropriate style was set to control the weight } \\
\text { of the fonts? }\end{array}$ & $\mathrm{O}$ \\
\hline $\begin{array}{l}3.4 .2 \\
\text { Letter Spacing }\end{array}$ & $\begin{array}{l}\text { Is spacing appropriately set to allow each letter to } \\
\text { be readable? }\end{array}$ & $\mathrm{O}$ \\
\hline $\begin{array}{l}3.4 .3 \\
\text { Word Spacing }\end{array}$ & $\begin{array}{l}\text { Is spacing appropriately set to allow each letter to } \\
\text { be readable? }\end{array}$ & $\mathrm{O}$ \\
\hline $\begin{array}{l}3.4 .4 \\
\text { Justification }\end{array}$ & $\begin{array}{l}\text { Is the flow of reads natural from left to right? } \\
\text { Are the sequence of each content displayed for the } \\
\text { correct reading sequence where the sequence affects } \\
\text { the meaning? }\end{array}$ & $\mathrm{O}$ \\
\hline $\begin{array}{c}3.4 .5 \\
\text { Margins and Borders }\end{array}$ & $\begin{array}{l}\text { Are margins between blocks and borders } \\
\text { appropriately set to distinguish contents? }\end{array}$ & $\mathrm{O}$ \\
\hline $\begin{array}{l}3.4 .6 \\
\text { Proximity of Related } \\
\text { Information }\end{array}$ & Are the related elements placed in close proximity? & $\mathrm{O}$ \\
\hline
\end{tabular}

\subsection{Usability Testing measured by KLM-GOMS}

Usability testing of each interface was conducted using KLM-GOMS [17][22]. The tasks were performed using both the existing menu interface and the optimized menu interface for the visually impaired users. The task to be performed was related to the topic, "obtaining a copy of your resident registration document from the civil complaint 24 
website" and the time spent performing the task was measured. The target task was only performed using mouse operation, and there was the condition that navigation through the website was limited to only the menu interface. The following table shows the analysis and assessment of the task procedures.

Table 11. Analysis of Performance Procedures using KLM-GOMS

\section{Existing Menu Interface}

Webpage scanning $(\mathrm{RM}) \rightarrow$ Recognizing the location of the menu area $(\mathrm{M}) \rightarrow$ Searching for the service menu to be used $(\mathrm{S}) \rightarrow$ Moving the cursor to the "civil complaint request " menu (P)

$\rightarrow$ Creating sub menu $\left(2^{\text {nd }}\right.$ menu $)$ window $(R) \rightarrow$ Submenu scanning $(\mathrm{SM}) \rightarrow$ Searching

"Internet civil complaint request " from the $2^{\text {nd }}$ menu $(\mathrm{S}) \rightarrow$ Putting the mouse over "the Internet civil complaint request" $(\mathrm{P}) \rightarrow$ Clicking "the Internet civil complaint request" $(\mathrm{B}) \rightarrow$ Completed $(\mathrm{RM})$

$$
\mathrm{SM} \rightarrow \mathrm{M} \rightarrow \mathrm{S} \rightarrow \mathrm{P} \rightarrow \mathrm{R} \rightarrow \mathrm{SM} \rightarrow \mathrm{S} \rightarrow \mathrm{P} \rightarrow \mathrm{B} \rightarrow \mathrm{RM}(7.7 \mathrm{~s})
$$

\section{Vertical Menu Interface}

Website scanning $(\mathrm{SM}) \rightarrow$ Searching for the service to be used from the new menu (S)

$\rightarrow$ Putting the mouse over "civil complaint request" menu $(\mathrm{P}) \rightarrow$ Clicking "civil complaint request" $(\mathrm{B}) \rightarrow$ Completed $(\mathrm{RM})$ $\mathrm{SM} \rightarrow \mathrm{S} \rightarrow \mathrm{P} \rightarrow \mathrm{B} \rightarrow \mathrm{RM}(3.9 \mathrm{~s})$

Block Menu Interface

Website scanning $(\mathrm{SM}) \rightarrow$ Searching for the service to be used from the new menu $(\mathrm{S})$

$\rightarrow$ Putting the mouse over "civil complaint request" menu $(\mathrm{P}) \rightarrow$ Clicking "civil complaint request" $(\mathrm{B}) \rightarrow$ Completed $(\mathrm{RM})$ $\mathrm{SM} \rightarrow \mathrm{S} \rightarrow \mathrm{P} \rightarrow \mathrm{B} \rightarrow \mathrm{RM}(3.9 \mathrm{~s})$

Table 12. Analysis of Task Time Spent on each Interface

\begin{tabular}{|c|c|c|c|c|c|c|}
\hline \multirow{3}{*}{ Key } & \multicolumn{2}{|c|}{ Existing Menu interface } & \multicolumn{2}{c|}{ Vertical Menu interface } & \multicolumn{2}{c|}{ Block Menu interface } \\
\cline { 2 - 7 } & Task steps & $\begin{array}{c}\text { Time spent } \\
(\mathrm{s})\end{array}$ & Task steps & $\begin{array}{c}\text { Time spent } \\
(\mathrm{s})\end{array}$ & Task steps & $\begin{array}{c}\text { Time spent } \\
(\mathrm{s})\end{array}$ \\
\cline { 2 - 7 } & 10 & 7.7 & 5 & 3.9 & 5 & 3.9 \\
\hline
\end{tabular}

The vertical and the block structure menu interfaces showed that the operation steps and the performance time were reduced by half as compared to those with the existing menu interface. The improved interface is displayed with a two-level menu hierarchy, and KLM-GOMS does not measure the mental operator (S) classified as recognition time; thus, no difference could be identified between the operation steps and time of the two interfaces.

\subsection{Average Hierarchical Size of Menu and Proportion of Menu Interface Occupying Screen}

When the vertical and the block structure menu interfaces are applied to a website, the interfaces should be consistently displayed for easy adaption and use by the user. This study analyzed the proportion of the menu area occupying the screen to evaluate the consistency of the interface displayed on the screen according to the number of menus in each interface. The experiments were performed on a 22 -inch LCD display with a resolution of $1920 \times 1080$. The experiment sites include 37 central administrative agency sites. 

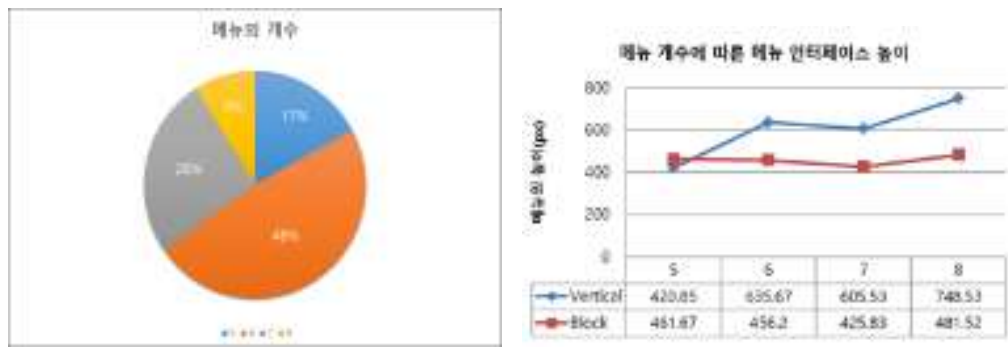

Figure 16. Statistics on Number of Menus at the Experiment Site Menus (left) and Height of Menu Interface Screen According to Number of Menus (right)

When each interface was applied to the experimental site, the difference in proportions occupying space was high according to the numbers of the primary and secondary menus in the menu. For the vertical structure menu interface, the height of the row in which the primary menu is arranged is determined according to the number of secondary menus. Moreover, if the number of primary menus is five or more, the height increases because more space is required due to the menu display in the new row. When the entire number of primary and secondary menus is large, scrolling down was required to view the existing screen that was filled up with the menus. Contrarily, for the block structure menu interface, the height of the space did not significantly increase compared to the vertical structure menu interface. Approximately $17 \%$ of the 37 websites have five or fewer primary menus and $83 \%$ have six or more primary menus. The average height of the space occupied by the vertical structure menu interface was $420.85 \mathrm{px}$ on average at the sites with five or fewer primary menus, and $663.24 \mathrm{px}$ on average at the sites with six or more primary menus. Thus, the height increased by approximately $66 \%$ in this manner. Moreover, in the case of the block structure menu interface. The average height of the space occupied by the vertical structure menu interface was $461.67 \mathrm{px}$ on average at the sites with five or fewer primary menus, and $454.51 \mathrm{px}$ on average at the sites with six or more primary menus, which showed no significant difference. Regardless of the number of menus, a more consistent menu interface could be displayed in the block structure menu interface.

\subsection{User Evaluation}

The most important aspect of interface evaluation is that the user directly evaluates the interface. This study evaluated the usability of the websites with vertical and block structure menu interfaces. The focus of usability experiments with users is on the actual usability and accessibility of the vertical structure menu interface and the block structure menu interface. Thus, this study compared and evaluated if the participants understood the structure of the menu well and used the menu easily.

\subsubsection{Participants for User Evaluation}

In the user evaluation, this study conducted an evaluation with two groups: nonvisually impaired and visually impaired groups. A total of 14 participants were in the experiments, with 6 non-visually impaired people and 8 visually impaired people. The non-visually impaired group consists of three males and three females with an average age of 27.5 years. The daily internet use by the non-visually impaired group was 5.3 hours per day. The visually impaired group consisted of five males and three females who were rated to have Level 3 of visual impairment. Four participants in the visually impaired group were members of the Rehabilitation 
Center for Visually Impaired Persons, who listened to computer information training for one hour per day on an average. The other four were low vision workers due to weak vision, while the four were in charge of computer work by using special glasses and small personal magnifiers. The four workers had a corrected vision of approximately 0.3 using wearable corrective tools. The average age of participants in the visually impaired group was 32.5 years.

\subsubsection{User Evaluation Design}

Among the central administrative agency sites, an existing site with the largest number of website menus and an existing site with the fewest number of the menus were selected. The selected sites were the 'Welfare Disability Employment Portal' and the 'Ministry of Health and Welfare.' Due to the small menu hierarchical structure of 'Welfare Disability Employment Portal,' the website had a small number of primary and secondary menus, while the 'Ministry of Health and Welfare' had a large number of primary and secondary menus. The tasks to be performed in the evaluation is the 'navigation' task, which is commonly used to evaluate the hierarchical data visualization [13].

\subsubsection{User Evaluation Procedure}

We first explained the structure of the menu interface before conducting experiments. The order of the navigation tasks was to find the primary menu in the order of the existing $\rightarrow$ vertical $\rightarrow$ block interfaces and further navigate the sublevel secondary menu. The participants were given free time to operate the menus. In the two experimental sites, a total of six sessions for designated tasks and free navigation tasks. The non-visually impaired group participated in experiments by applying the interface to their computer environment, and the visually impaired group participated in experiments by 1:1 experiment environment by considering the computer use level of the participants. After conducting the experiment, we conducted a questionnaire evaluation to determine subjective opinions and preferences for the interfaces.

\subsubsection{Analysis of User Evaluation Results 1 - Non-visually Impaired Group}

After the user evaluation, the group of non-visually impaired people was asked to fill out a questionnaire. The evaluation items and results of the questionnaire are as follows. Items were created to evaluate the degree of usability at each interface, which was evaluated on a 7-point scale.

\section{Table 13. 7-point Scale Questionnaire Assessment for Visually Impaired Group}

\begin{tabular}{|l|c|c|c|}
\hline \multicolumn{1}{|c|}{ Questionnaire content } & existing & Vertical & Block \\
\hline Q1. Easy to understand structure of menu on website & 3.0 & 5.6 & 4.1 \\
\hline Q2. Convenient for performing given tasks & 3.0 & 5.8 & 4.0 \\
\hline Q3. Preferred for performing tasks & 2.8 & 6.1 & 4.3 \\
\hline
\end{tabular}

The non-visually impaired group showed the preference for the vertical structure menu interface between the vertical and the block structure menu interfaces. There was no restriction on the eye movement and the participants were used to using the internet; thus, the participants were freely engaged in screen scrolling and navigation tasks on the vertical menu. According to the user feedback, vertical menus were arranged in a single line; thus, it was convenient to quickly skim down 
the first letter of each menu in a downward direction when looking for a secondary menu. Moreover, the block structure menu was arranged in two lines; thus, the participants had to skim the menus zigzag or read them clockwise to find the secondary menus, which delayed the navigation. Nevertheless, both the vertical and the block structure menus were easier to view than the menus provided by the existing website due to the larger size of each menu and the easy display of the secondary menus.

\subsubsection{Analysis of User Evaluation Results 2 - Visually Impaired Group}

The results of the questionnaire content and evaluation results on the group of the visually impaired people are as follows. Considering the evaluation level of the visually impaired people, they were asked to select one interface for the questionnaire item.

Table 14. Questionnaire Assessment of Visually Impaired Group

\begin{tabular}{|c|c|c|c|}
\hline Questionnaire content & existing & Vertical & Block \\
\hline $\begin{array}{l}\text { Q1. Which screen is easy to understand structure of the website } \\
\text { menu? }\end{array}$ & 0 & 1 & 7 \\
\hline Q2. Which screen is easy to use for performing tasks? & 0 & 1 & 7 \\
\hline Q3. Which screen was most difficult to use for performing tasks? & 7 & 0 & 1 \\
\hline
\end{tabular}

First, we select one interface for each question to determine the preference of the interface. The overall evaluation comment was compared to the existing website menu, that the vertical and the block structure menus were overall set to darker colors, which soothed the eyes and were easier to view.

For the vertical structure menu, the website with a small number of menus ('Welfare Disability Employment Portal') did not make any big difference, but on a website with a large number of menus (the 'Ministry of Health and Welfare'), the height of the screen increased according to the number of secondary menus; thus, requiring the scrolling operation to read the screen that was blocked by the new menus. In this case, the participants said it was more familiar and comfortable to read the screen on an existing website because a submenu appeared when the user hovered the mouse over the primary menu.

One participant, who evaluated the vertical structure menu interface as the most convenient, selected the block structure interface as the most difficult interface. This participant was an office worker who was in charge of ordering supplies at work. Assuming the participant was doing his or her office job with menus, the vertical structure menu interface would be more convenient than the block structure menu interface because the vertical structure menu interface was arranged in a single-line list, which makes it easier to search the products. This result confirmed that the people with low vision preferred the block structure menu interface.

\section{Conclusions}

This study designed optimized menu interfaces for the people with low vision, who experience difficulty in accessing websites composed of visual contents. Further, this study proposed two types of menu interfaces with vertical and block structures according to the hierarchical representation methods. Those interfaces were designed in accordance with the web accessibility guidelines and in consideration of the visual environment of the people with low vision. Furthermore, the requirements derived from the characteristics of web use and practical experience of the people with low vision. The actual accessibility and usability of 
the proposed menu interfaces were evaluated. This study used the web accessibility tools to check the contrast ratio of the improved menu interfaces, which complied with Level AAA for all the elements. In the efficiency evaluation of the page navigation, KLM-GOMS, an analytical evaluation tool, showed a reduction in performance duration by half with the improved menu interfaces as compared to those with the existing sites. To evaluate the satisfaction parameter, this study performed an end-user evaluation by dividing the participants into two groups, such as non-visually impaired and visually impaired groups. As a result, the non-visually impaired people preferred the vertical structure menu interface and the visually impaired people preferred the block structure menu interface. Considering the internet use level and the visual environment by the people with low vision, this study could verify that the block structure menu interface, which makes the menu structure easily understandable and the secondary menu to be viewed consistently without scrolling, was more suitable for the people with low vision.

\section{Acknowledgments}

This work was supported by the National Research Foundation of Korea (NRF) grant funded by the Korean Government (Ministry of Science and ICT) (No. NRF2016R1A2B4016591).

\section{References}

[1] MSIP, NIA, "The Report on the Digital Divide", (2016)

[2] Ministry of Health and Welfare Disabled person registration status, (2017).

[3] W3C, "Web Content Accessibility Guidelines (WCAG) 2.0", (2008).

[4] Kyongsik Kim, "Learn about web accessibility tools for people who are blind", Ablenews, (2015).

[5] Ableforum, "Public institution website Survey on usability of the disabled.", (2008).

[6] MIST, "Korean Web Accesibility Guideline : KWCAG2.0", (2010).

[7] Structures and links(website), https://www.bbc.com/education/guides/z96psbk/revision, (2018).

[8] http://whatis.techtarget.com/definition/menu, (2018).

[9] D. Lowe and M. Gaedke, Web Engineering: 5th International Conference, ICWE 2005, Sydney, Australia, July 27-29, 2005, Proceedings, Springer, vol. 3579, (2011).

[10] J. Nielsen, “Sun Microsystem’s 1997 Web Design”, Nielsen Norman Group, (1998).

[11] Website Navigation, http://www.webpagemistakes.ca/website-navigation/, (2018).

[12] Navigation, http://www.homejjang.com/11/navigation.php, (2018).

[13] H. Song, B. Kim, B. Lee and J. Seo, "A comparative evaluation on tree visualization methods for hierarchical structures with large fan-outs", Proceedings of the SIGCHI Conference on Human Factors in Computing Systems. ACM, (2010).

[14] Tree, http://slidesplayer.org/slide/11290968/, (2016)

[15] Usability, http://en.wikipedia.org/wiki/Usability, (2018).

[16] Usability, http://cmos00.tistory.com/1977, (2017).

[17] Y. Cho, S. Han, K. Lee, G.-S. Jung and J. Cha, "Study on the usability testing for voice-controlled user interface", focused on IPTV usage, (2017).

[18] J. de Luca, "The Importance of User Research and How To Do it", careerfoundry, (2016).

[19] Y. Kim and S. Nam Byun, "Domestic potable telephone UI (User Interface) comparative study that use GOMS", KIIE:Korean Institute of Industrial Engineers), (2004), pp. 881-888.

[20] J. Kim, "Human computer interaction introduction", ahn graphics publishers, Seoul, (2005).

[21] S. K. Card, T. P. Moran and A. Newell, "The Psychology of Human-Computer Interaction", CRC Press, (2017).

[22] S. K. Card, T. P. Moran and N. Allen, "The keystroke-level model for user performance time with interactive systems", Communications of the ACM, vol. 23, no. 7, (1980), pp. 398-400.

[23] W3G, "Accessssibility Requirements for People with Low Vision", (2016).

[24] M. Okabe and K. Ito, "Color Universal Design (CUD) How to make figures and presentations that are friendly to Colorblind people", (2002).

[25] Web navigation, https://en.wikipedia.org/wiki/Web_navigation, (2018).

[26] Colin Ware, "Information Visualization : Perception for Design", Elsevier, (2012).

[27] https://www.worktogether.or.kr/, (2018).

[28] http://kostat.go.kr/, (2018).

[29] W3C, "Understanding Success Criterion 1.4.3: Contrast", (2018).

[30] WebAIM, "WebAIM:Color Contrast Checker", (2018). 
International Journal of Advanced Science and Technology

Vol.119 (2018) 